\title{
Students Engagement and Evaluation of Personalized Learning Practices in Class
}

\author{
José María Carazo Abolafia \\ Universidad de Navarra \\ Spain
}

\begin{abstract}
Students in regular in-person education are not familiarized with personalization in class. They are not used to learner's agency, self-paced learning, or learner-driven learning. All these facets of personalized learning boost students' freedom and accountability. Since they are the leading player in their learning processes, their opinions on the new practices in class give us an idea of how successful the personalization of learning is and to what point they are a good fit with this methodology.
\end{abstract}

\section{Introduction}

The case study in this research analyzes the last five academic years using teaching methodologies to personalize learning in class. Those methodologies appeal to students' accountability. Academic success becomes more dependent on them since they are free to decide their learning pace or when to be assessed, and eventually, they have some voice and choice on the contents of the syllabus. This case study analyzes two different 32-week courses about computer sciences that students usually take simultaneously. Both courses are part of a Vocational Training program about software development. Students are mainly young adults, all over 18. In this paper, the researcher used personalization and individualization indistinctly. Though there are differences, the extension of this work does not make it possible to distinguish between those two terms.

\section{Theoretical Background}

Over the last decades, different theories sustained a shift in teaching practices. Learner-Centered Teaching advocates for students' autonomy, accountability, and voice and choice. At the same time, the teacher's role changes to a less authoritarian one. In other words, the instructor stops being the main character. Moreover, "the goal of learnercentered teaching is the development of students as autonomous, self-directed, and self-regulated learners" [1]. The same happens with the personalization of learning. Despite a generalized controversy on the terms, it is widely agreed that students have to become autonomous learners [2][3]. This point -among others- shows how learner- centered teaching and personalization are closely connected [4][5]. Self-regulation is tied to both insights. Students' autonomy, leadership when learning, and voice and choice are personalized learning and learner-centered teaching notes. They are also present in the more accepted models of selfregulation [6]. All those theoretical backgrounds underline the student's agency, up to becoming a partner for the teacher [1]. Consequently, a learnercentered and personalized approach cannot succeed without the learner's partnership. Therefore, students' evaluation of personalized teaching is relevant. That evaluation can be taken as an indicator of personalization's success -or failure.

In other words, given the student's role, we cannot advocate for personalized instruction if students feel lost, are not engaged, or are not willing to learn in that way. In traditional teaching, students' opinions on instruction had little value. Under this new paradigm, it is quite the opposite.

\section{Students' Accountability}

Personalized learning requires some skills from the student's side. Consequently, students may not be well prepared for personalized learning and may need training [1][3]. Most of our students come from High School. Others come from vocational training programs for non-adults. We found that all of them, especially those from high school, are not used to nor naturally prepared to drive their learning, learn by experimenting instead of being lectured, and make decisions regarding their learning. Therefore, personalization makes them struggle since this methodology requires students' agency [7], self-paced learning [8], and their having -and exercising voice and choice [9]. In other words, there are great benefits when students can exercise their freedom in their learning process [10]. Some norms, boundaries, and purpose are necessary to ensure that students use their freedom in a meaningful and beneficial way [11].

\section{Practices and tools used to personalize learning}

There are several teaching practices implemented to individualize and personalize learning. The convenience and use depend on the subject. The case 
study in question focuses on two courses, as mentioned before. One is about server deployments, and the other is about databases. Different tools and teaching practices apply to either one or both.

\subsection{Personalized one-to-one assessment}

The personalized one-to-one assessment method applies to servers course. Students are assessed individually in a student-to teacher conversation. The teacher ensures the student's mastery by asking questions and assigning practical tasks. The course using this method contains a sequence of learning targets that students have to master. Once their mastery of one particular target is certified by the teacher, they can move on to the next one. Examples of learning targets are deploying an ecommerce site, configuring security measures, or setting DNS domain names. Complex targets can be divided into minor ones.

\subsection{Blended learning}

By blended learning, we mean using online courses in regular in-person classes. This approach is also called hybrid learning [12]. Online courses give students the possibility to learn at their own pace. With the proper content, they have more autonomy to learn. Additionally, multimedia content help to enlarge the syllabus since students learn more deeply and faster [13]. The databases and server courses have their related online courses. These online resources are like textbooks. There are no actual textbooks. Their contents include a considerable number of videos recorded in class.

\subsection{Individual Assignment Delivery}

Students practice what they learn in the database course, working on a set of assignments as they move on along the academic year. There are more than 50 assignments that each student completes at their own pace. Consequently, they can even adjust the exams calendar by crafting their own timetable for exams. One goal is that students do not pass to the following task until they have completed and understood the previous one, no matter how much time it takes. No one is pushed or stopped, except for the course deadline. Worksheets are sent using Google Drive. When each student asks for the following assignment, they instantly receive a Google document with it. This document includes the answer key to the preceding worksheet. A web application has been developed to facilitate individual deliveries.

\subsection{Flexible syllabuses}

The databases and servers' courses, have a flexible syllabus. Each student can choose not to complete specific assignments tagged as not required-to-pass. Those assignments are the latest ones, and students start to work on them only if they have completed all the previous tasks, which are compulsory. Additionally, when students reach the last part of the syllabus, they must outline it. Thus, in the database course, they have to design a computer program for any purpose they want. They usually take a problem related to their own lives or to their relatives. There are some requirements regarding functionality and design.

In the servers' course, they can pick up any topic related to servers or software development that they want. Again, they only must comply with a minimum work volume. In this case, they are also required to document their work and publish it on the Internet, in case any peers are interested. These projects weigh $20 \%$ of the final grade in the database course and $30 \%$ in the server's class. These optional final works require some learning autonomy on the student side. Of course, they can count on the teacher's support. However, they often choose to work on something barely known by the teacher. It is worth mentioning that this is not usually a problem since, at that point, they have acquired the necessary autonomy.

\section{Students' Perception and Evaluation of Personalized Teaching Practices}

Since the 2017/18 academic year, students fill a questionnaire to value the tools and practices described before. Unfortunately, there was no survey during the last year due to the pandemic. That means that we can compare the results of 3 different years. Students are asked to fill the survey in class simultaneously, someday close to the end — students who answered the questionnaire the year before are excluded. Also, students with high rates of absenteeism are not given the survey. These rules have the inconvenience of reducing the number of participants, up to 10 or 15 per year. One may think that those are poor numbers, which is why the same survey has been repeated in consecutive years with different students in the same course. Finally, all answers to the questionnaire are entirely anonymous.

\subsection{Survey questions}

There are 21 questions divided into three parts: one about the use of videos on YouTube. Another about the tools and applications used to personalize learning and the final optional projects. The last part is about teaching practices regarding personalization. All the questions are shown in Table 1. All questions except one are answered with a 5 points scale. 5 is the most favorable answer for personalizing practices except for self-paced learning-questions 18 to 20 . Free comments and observations are allowed at the end of the first part. 
Table 1. Questions in the survey

\begin{tabular}{|c|c|c|}
\hline \multirow{9}{*}{$\begin{array}{l}\text { PART I. } \\
\text { Multimedia content }\end{array}$} & 1 & How bad would the idea be of shutting down the YouTube channel for class? \\
\hline & 2 & Does the channel help you to learn? \\
\hline & 3 & In general, with the YouTube channel you learn more or less? \\
\hline & 4 & Does the YouTube channel help you to learn more when you study at home? \\
\hline & 5 & $\begin{array}{l}\text { With the channel I learn to learn by myself, and I dare to investigate on my own. } \\
\text { Agreed? }\end{array}$ \\
\hline & 6 & Videos in class are a good tool to learn. \\
\hline & 7 & With videos in class, I learn faster. \\
\hline & 8 & Finally, how positive do you consider your experience? \\
\hline & 9 & Write here if you want your observations and suggestions \\
\hline \multirow{8}{*}{$\begin{array}{l}\text { PART II. Tools and } \\
\text { final optional } \\
\text { proyects }\end{array}$} & 10 & Instant assignment delivery with Google Drive Documents \\
\hline & 11 & Blended Learning -online platform in class \\
\hline & 12 & SQL web for practice -sql.ldts.es. \\
\hline & 13 & YouTube channel for Database design \\
\hline & 14 & YouTube channel for SQL \\
\hline & 15 & YouTube channel for Server deployment \\
\hline & 16 & Server course final optional project \\
\hline & 17 & Database course final optional project \\
\hline \multirow{4}{*}{$\begin{array}{l}\text { PART III. } \\
\text { Teaching practices }\end{array}$} & 18 & SQL exercises: 1 for self-paced, 5 for the same pace for all \\
\hline & 19 & Design exercises: 1 for self-paced, 5 for the same pace for all \\
\hline & 20 & Learning targets in servers course: 1 for self-paced, 5 for the same pace for all \\
\hline & 21 & Regarding having learning targets instead of exams in the servers course \\
\hline Consent & 22 & $\begin{array}{l}\text { Check "No problem" if you allow the results of this survey to be used anonymously } \\
\text { for research. }\end{array}$ \\
\hline
\end{tabular}

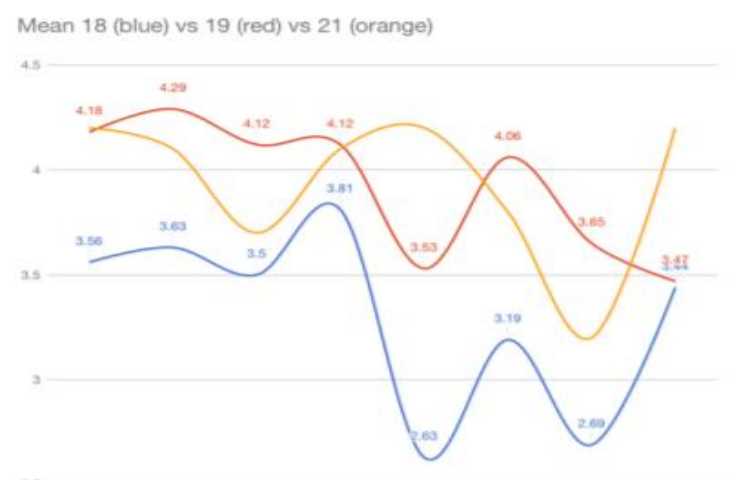

Figure 1. Mean of answers for questions 1 to 8 for every academic year

\subsection{Survey results}

Figures 1 and 2 show the mean for every question in the survey. Along the three academic years, 43 students have filed the questionnaire.

5.2.1. Video content on YouTube - According to the responses, shooting down the YouTube channel

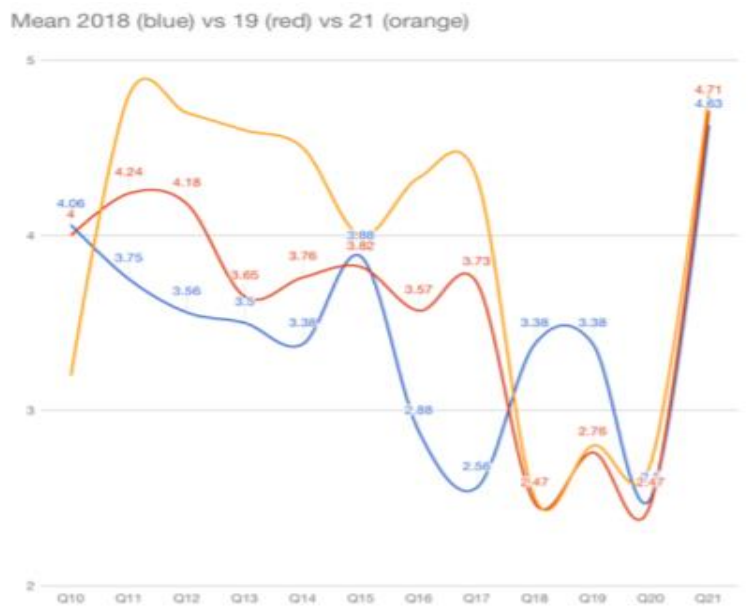

Figure 2. Mean of answers for questions 10 to 21 for every academic year

containing all the video recordings would be a terrible idea (3.95 out of 5) since it helps learn (4 out of 5). Many students even think that they learn more with videos (3.79 out of 5), especially at home (4 out of 5). Most people agree that it is a good tool for learning (3.67 out of 5). However, contrary to our point of view [13], they do not entirely agree that they learn faster with video content (only 3.19 out of 5). When asked 
if they consider their experience a positive one, the resulting mean is 3.63 out of 5 . Data from the first part of the questionnaire are consistent with questions 13 to 15 . They are asked for the YouTube channel in three different subjects: database design, database SQL language, and server deployment. The evaluation of this tool varies between 3.79 and 3.88 out of 5 .

\subsubsection{Tools used to individualize learning pace -} As mentioned before, there are a few resources that allow individualization. Students are asked about these tools, and later, they are asked about self-paced learning. Blended learning is considered to be a great teaching approach (4.19 out of 5). The application used to deliver database worksheets individually is also highly appreciated (4.07 out of 5). However, there is controversy regarding the self-paced approach in class -questions 18 to 20. These questions are inverted, meaning that one stands for "self-paced is the best approach", while five means "all at the same pace is the best thing". Three would mean something like "nothing is better". This way, students' awareness is boosted when answering these questions. Regarding the server deployment course, 17 students out of 43 say that self-paced learning is much better, and six more would say that it is better - the mean results in 2.53 out of 5. Regarding the database course, the mean is 2.81 when learning SQL language and 3.0 when learning database design. Self-paced learning is preferred by a rough $50 \%$, while $10 \%$ have no preference. The variance is the highest with these questions -between 1.56 and 1.52. Such is the disparity of opinions among the respondents.

\subsubsection{Learning targets and flexible syllabus -} Final non-mandatory projects give students great freedom to learn according to their interests and choices. This idea applies to the server course and the database course. However, not all students value this approach (3.46 and 3.4, respectively). A different case is having learning targets and one-to-one assessments instead of examinations. There we find an astonishing 4.7 out of 5 with a slight standard deviation.

5.2.4. Differences after the pandemic - It is worth mentioning how the academic year after the pandemic gives more value to personalizing practices. Thus, after 2020/21, the students see blended learning, video content, and the final optional projects as more beneficial than previous years. Nonetheless, we must clarify that only ten students filled the survey this last year.

\section{Discussion}

Criticism against this study may argue that numbers are insufficient for statistical significance, which cannot be denied. However, this study is not a lab experiment or carried out along a vast number of classes.

In statistical studies, classes have little or nothing to do with the researchers, while in this study, the teacher is the researcher himself. The quid lies in whether a teacher can or cannot do authentic research within their professional practice. Several theories advocate for that kind of research, like Design Based Research, "used to study learning in environments that are designed and systematically changed by the researcher" [14]. It is most interesting to notice that "contrary to the arguments of those pushing for experimental designs as the gold standard- the messiness of real-world practice must be recognized, understood, and integrated as part of theoretical claims if the claims are to have real-world explanatory value" [14]. Not acknowledging the complexity and limitations of an actual context may probably cause research disconnected from the real world, the real schools, and the real classes, making it challenging to find analysis with value for real teachers [15]. Such closeness to actual classrooms is one of the primary purpose of this paper.

\section{Conclusion}

The success of personalized learning and learner centered teaching in regular in-person classes depends on the student. They must assume active roles and exercise their freedom in a meaningful and beneficial way for learning. Therefore, their opinions on the tools and teaching practices used to personalize learning can give us an idea of to what extent they are a good fit with this methodology. Contrary to our expectations, this case study found some controversy regarding self-placed learning. It is not widely perceived as better than a same-pace-for-all, which is the approach they were used to - nonetheless, students like the tools and teaching practices behind learning personalization.

\section{References}

[1] Weimer, M. (2013) Learner-Centered Teaching. Five key changes to practice, Jossey-Bass, San Francisco.

[2] Prain, V., Cox, P., Deed, C., Dorman, J., Edwards, D., Farrelly, C., Yager, Z. (2013). Personalised learning: Lessons to be learnt. British Educational Research Journal, 39(4), 654-676.

[3] Deed, C., Cox, P., Dorman, J., Edwards, D., Farrelly, C., Keeffe, M., Yager, Z. (2014). Personalised learning in the open classroom: The mutuality of teacher and student agency. International Journal of Pedagogies and Learning, 9(1), 66-75. DOI:10.1080/18334105.2014.11082020.

[4] Jones y McLean (2012). Personalising Learning in Teacher Education through the Use of Technology. Australian Journal of Teacher Education, 37(1), 75-92. DOI:10.14221/ajte.2012v37n1.1. 
[5] Lee, D., Huh, Y., Lin, C.-Y., and Reigeluth, C. M. (2018). Technology functions for personalized learning in learner-centered schools. Educational Technology Research and Development, 66(5), 1269-1302. DOI:10.1007/s11423 $-018-9615-9$

[6] Panadero, E. (2017). A Review of Self-regulated Learning: Six Models and Four Directions for Research. Frontiers in Psychology, 8, 422. DOI:10.3389/fpsyg.2017.0 0422.

[7] Ualiyeva, N. T., and Murzalinova, A. Z. (2016). Organization of Individual Work of Students under Competence-Oriented Approach to Education in Higher School. International Journal of Environmental and Science Education, 11(14), 6540-6556.

[8] Paz-Albo, J. (2017). Is Personalized Learning the Future of School? Childhood Education, 93(4), 295-299. DOI:10.1 080/00094056.2017.1343581.

[9] Dalland, C. P., and Klette, K. (2016). Individual teaching methods: Work plans as a tool for promoting self-regulated learning in lower secondary classrooms? Education Inquiry, 7(4), 381-404. DOI:10.3 402/edui.v7.2 8249.

[10] Netcoh, S. (2017). Balancing freedom and limitations: A case study of choice provision in a personalized learning class. Teaching and Teacher Education, 66, 383-392. DOI:10.1016/j.tate.2017.05.010.

[11] Lindner K.-T., Alnahdi G. H., Wahl S., and Schwab S. (2019). Perceived Differentiation and Personalization Teaching Approaches in Inclusive Classrooms: Perspec tives of Students and Teachers. Front. Educ. 4:58. DOI:10.3 389/feduc.2019.00058.

[12] Young, J. R. (2002, March 22). 'Hybrid' teaching seeks to end the divide between traditional and online instruction. The Chronicle of Higher Education, A33.

[13] Carazo Abolafia, J. M. (2021). A Case Study of Learning Personalization in Class Based on Blended Learning with Multimedia Content. Literacy Information and Computer Education Journal (LICEJ), 12(1). doi:10.20533/licej.2040.2589.2021.0462.

[14] Barab, S. (2014). Design-Based Research: A Methodological Toolkit for Engineering Change. In R. Sawyer (Ed.), The Cambridge Handbook of the Learning Sciences (Cambridge Handbooks in Psychology, pp. 151170). Cambridge: Cambridge University Press. DOI:10.1 017/CBO9781139519526.011.

[15] Valverde-Berrocoso, J., Fernández-Sánchez, M. R., Garrido-Arroyo, M. del C., Malinverni, L., and Revuelta Domínguez, F. I. (2020). Investigación basada en diseño (DBR). In Caminos y derivas para otra investigación educativa y social (pp. 167-180). 